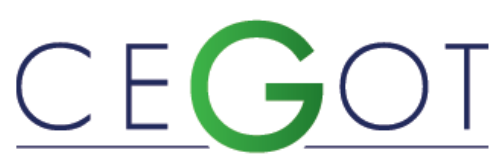

Centro de Estudos de Geografia e Ordenamento do Território

\section{GODINHO VERRAN, PEDRO}

Universidade Federal do Rio Grande do Sul

Programa de Pós-Graduação em Geografia

91501-900, Porto Alegre, Brasil

pedroverran@gmail.com

MARQUES STROHAECKER, TÂNIA

Universidade Federal do Rio Grande do Sul

Programa de Pós-Graduação em Geografia

91501-900, Porto Alegre, Brasil

tania.strohaecker@ufrgs.br

\title{
PROPOSTA METODOLÓGICA PARA IDENTIFICAÇÃO DE ÁREAS CARENTES DE EQUIPAMENTOS \\ DE ENSINO INFANTIL NO MUNICÍPIO DE PORTO ALEGRE/RS
}

METHODOLOGICAL PROPOSAL FOR IDENTIFICATION OF UNIFIED AREAS OF EARLY CHILDHOOD EDUCATION

EQUIPMENTS IN THE MUNICIPALITY OF PORTO ALEGRE / RS

Referência: Godinho Verran, Pedro; Marques Strohaecker, Tânia (2021). PROPOSTA METODOLÓGICA PARA IDENTIFICAÇÃO DE ÁREAS CARENTES DE EQUIPAMENTOS DE ENSINO INFANTIL NO MUNICÍPIO DE PORTO ALEGRE/RS. Revista de Geografia e Ordenamento do Território (GOT), no 22 (Dezembro). Centro de Estudos de Geografia e Ordenamento do Território, p. 200 - 229, dx.doi.org/10.17127/got/2021.22.009

\section{RESUMO}

O objetivo dessa pesquisa foi apresentar uma proposta metodológica de identificação de áreas carentes de equipamentos de ensino infantil no município de Porto Alegre/RS, através do uso de ferramentas de Geoprocessamento. A metodologia contemplou dados do censo demográfico e do censo escolar, os quais foram manipulados através de ferramentas de Geoprocessamento para a geração de mapas temáticos. O mapeamento foi realizado em duas escalas de análise. Na primeira escala de análise, o município foi dividido em 17 regiões, e duas dessas regiões foram selecionadas para análises mais específicas por possuírem baixas taxas de atendimento ao ensino infantil. Na segunda escala de análise, as duas regiões selecionadas previamente foram mapeadas com um maior nível de detalhamento, através do método dasimétrico. Além disso, foram mapeados os pontos com as coordenadas geográficas de creches e pré-escolas para a geração de raios de recrutamento, com a finalidade de se identificar as áreas com baixas condições de acesso a esses equipamentos. Dessa forma, foram identificadas duas áreas prioritárias para a instalação de creches e duas áreas para a instalação de pré-escolas. Como as bases de dados utilizadas nesta pesquisa possuem abrangência nacional, o uso dessa metodologia possibilita a comparação das diferentes realidades da oferta e demanda ao ensino infantil entre os municípios brasileiros.

Palavras-chave: Geoprocessamento; análise espacial; método dasimétrico, raio de recrutamento; ensino infantil. 


\section{ABSTRACT}

The objective of this research was to present a methodological proposal for the identification of areas lacking equipment for early childhood education in the municipality of Porto Alegre / RS, using Geoprocessing tools. The methodology included data from the demographic census and the school census, which were manipulated through Geoprocessing tools for the generation of thematic maps. The mapping was performed on two scales of analysis. On the first scale of analysis, the municipality was analyzed divided into 17 regions, with two regions being selected for more specific analyzes, as they have low rates of attendance to early childhood education. In the second scale of analysis, the two selected regions were mapped with a greater level of detail, using the dasimetric method. In addition, were mapped points with the geographic coordinates of daycare centers and preschools for the generation of recruitment rays, in order to identify the areas with low conditions of access to this equipment. Thus, two priority areas were identified for the installation of daycare centers and two areas for the installation of preschools. Considering that the databases used in this research are national in scope, the use of this methodology makes it possible to compare the different realities of supply and demand for early childhood education among Brazilian municipalities.

Keywords: Geoprocessing; spatial analisys; dasimetric method; recrutment ray; early childhood education.

\section{Introdução}

O Plano Nacional de Educação (PNE) de 2014 determina que compete à União, aos Estados, ao Distrito Federal e aos Municípios atuarem em regime de colaboração, visando o alcance das metas e a implantação das estratégias e objetivos do PNE (Brasil, 2014). Dessa forma, os sistemas de educação dos Estados, do Distrito Federal e dos Municípios devem criar os seus respectivos planos de educação, com a finalidade de gerir a educação na sua totalidade, através de um regime de colaboração entre as diversas instâncias do poder público.

No caso do PNE, realizar um diagnóstico preciso da realidade educacional brasileira e, a partir disso, extrair as demandas sociais que irão nortear as políticas públicas educacionais é um procedimento complexo, tendo em vista não só a grande extensão territorial brasileira ou o seu enorme volume populacional, mas também a grande diversidade socioeconômica e cultural entre os diferentes estados e municípios do país. Embora um diagnóstico geral do sistema educacional do país seja fundamental, as medidas pontuais de intervenção devem ser realizadas a partir de análises intraurbanas dos territórios municipais. 
Dessa forma, confere-se à escala municipal um maior nível de detalhamento no planejamento e na tomada de decisão em ações de políticas públicas educacionais, se comparado às escalas federal e estadual, afinal, são os agentes municipais que estão em maior contato com as demandas da população, o que possibilita uma análise mais eficaz no que se refere à identificação de problemas educacionais locais.

Em áreas urbanas de pequeno porte, os gestores locais têm melhores condições de inspecionar diretamente cada escola, bem como podem dialogar com a população, por apresentarem maior facilidade em identificar as situações de pressão da demanda por vagas. No entanto, este problema torna-se muito mais complexo nos municípios de grande porte, uma vez que tal gestão pode envolver milhares de escolas, bem como nas áreas urbanas em permanente expansão (Torres, 2005).

Nesse sentido, o uso de técnicas de Geoprocessamento assume papel primordial, visto que permite a manipulação de dados de diversas fontes, permitindo o cruzamento dessas informações ao utilizar técnicas espaciais e a posterior representação geográfica dos fenômenos em mapas temáticos. O uso do Geoprocessamento permite a orientação de um dos maiores problemas no estudo da implantação de políticas públicas educacionais, que é a questão de onde agir. $\mathrm{O}$ ganho em precisão e velocidade que essa ferramenta proporciona é muito importante, o que fica patente no ambiente da administração pública, onde muitas tarefas rotineiras, de execução monótona e demandadoras de grande quantidade de tempo, podem ser beneficiadas com a informatização (Souza, 2001).

O objetivo dessa pesquisa é apresentar uma proposta metodológica de identificação de áreas carentes de equipamentos de ensino infantil, a partir de um estudo de caso no município de Porto Alegre/RS, através do uso de ferramentas de Geoprocessamento. A otimização dos custos de implantação de equipamentos de ensino infantil passa, necessariamente, pela análise locacional como fator de relevância para a qualificação dos serviços públicos. 


\section{Critérios para a análise da distribuição espacial de escolas no ambiente intraurbano}

Em cada escala de planejamento devem ser tomadas determinadas decisões utilizando-se dados e análise de caráter particular. Assim, para o estabelecimento de políticas gerais de localização, a análise deve incidir sobre dados agregados por frações territoriais adequadas, que podem variar desde o país até ao município, dependendo da abrangência espacial do planejamento. No entanto, para a decisão das ações a serem exercidas na escala intraurbana, a análise deve envolver as questões de localização e acessibilidade referentes a cada um dos equipamentos de ensino (Arantes, 1986).

Para o presente trabalho, a acessibilidade deve ser entendida como a possibilidade de deslocamento de pessoas, bens e informações entre dois ou mais pontos distribuídos pelo espaço (Arantes, 1986), por se constituir em uma variável que decresce com o tempo de deslocamento e por estar diretamente relacionada à distância a ser percorrida (Nahas, 2013).

A fim de sintetizar as diferentes condições de acessibilidade dos equipamentos de ensino, Brau et al (1980) indicam uma hierarquia das condições de acessibilidade da unidade educacional em relação à população do entorno, conforme mostra a Tabela 1.

Tabela 1 - Condições de acessibilidade para equipamentos de ensino

\begin{tabular}{|l|l|l|l|}
\hline Acessibilidade & \multicolumn{1}{|c|}{ Ensino Infantil } & Ensino Fundamental & \multicolumn{1}{|c|}{ Ensino Médio } \\
\hline Excelente & menos de $250 \mathrm{~m}$ & menos de $250 \mathrm{~m}$ & menos de $250 \mathrm{~m}$ \\
\hline Ótima & $250-500 \mathrm{~m}$ & $250-500 \mathrm{~m}$ & $500-1000 \mathrm{~m}$ \\
\hline Regular & $500-750 \mathrm{~m}$ & $500-750 \mathrm{~m}$ & $1000-2000 \mathrm{~m}$ \\
\hline Baixa & $750-1000 \mathrm{~m}$ & $750-1000 \mathrm{~m}$ & $2000-3000 \mathrm{~m}$ \\
\hline Péssima & acima de $1000 \mathrm{~m}$ & acima de $1000 \mathrm{~m}$ & acima de $3000 \mathrm{~m}$ \\
\hline
\end{tabular}

Fonte: Brau, Mercê e Tarrago (1980). 
Uma forma de se analisar as condições de acessibilidade de um grande número de equipamentos de ensino em um município de grande porte com relação à população do entorno é através da geração dos raios de recrutamento desses equipamentos. A dimensão dos raios poderá fornecer informações sobre como está distribuída a acessibilidade às escolas no espaço intraurbano. Nesse sentido, o raio de recrutamento está diretamente relacionado ao conceito de acessibilidade como medida de distância e se refere à circunferência medida em metros na qual teoricamente se localiza a residência dos alunos, tendo a escola como centro do círculo.

No entanto, avaliar a acessibilidade levando-se em consideração apenas o fator distância implica em desconsiderar diversos outros fatores que podem comprometer o deslocamento do aluno até a escola. Dentre esses fatores, podemos destacar a topografia, a hidrografia, o sistema viário, os diversos usos e atividades vinculados ao solo urbano, entre outros.

Os desníveis topográficos significativos podem comprometer a continuidade espacial, e, portanto, a acessibilidade de parte da população. Em áreas acidentadas o esforço físico despendido para vencer uma distância é maior que em uma região plana e sem barreiras significativas (Ferrari, 1978 apud Arantes, 1986). Com relação à hidrografia, mesmo dispondose de elementos de transposição, os cursos d'água, lagos e represas afetam a acessibilidade porque aumentam as distâncias a serem percorridas entre pontos separados por algum desses acidentes. Já o sistema viário, conquanto seja um elemento garantidor do acesso, pode também constituir-se em barreira física do ponto de vista da rede escolar, caso as vias apresentem trânsito pesado e intenso, assim como a falta de pavimentação e calçamento das ruas. Além desses elementos, considera-se que nos centros urbanos ocorram atividades e usos do solo que, por seu caráter extensivo, podem comprometer a continuidade espacial, como por exemplo: instalações militares e aeroportuárias; reservas florestais, grandes estabelecimentos industriais etc. (Arantes, 1986)

Embora em muitas situações seja inviável considerar todos os elementos que podem afetar a análise da acessibilidade dos estudantes às escolas, o pesquisador deve identificar e selecionar os elementos que considere fundamentais para a representação cartográfica. Apesar de a elaboração de mapas com a localização dos prédios escolares e outras informações não possibilite esgotar a complexidade do tema, sem dúvida pode ajudar a compreender o contexto espacial no qual a escola está inserida. 
Como primeiros trabalhos que apresentaram o conceito de acessibilidade relacionado aos raios de recrutamento de equipamentos de ensino, podemos citar: Planejamento de Rede Escolar: proposta metodológica (CEBRACE, 1981); Planejamento de rede escolar: questões teóricas e metodológicas (Arantes, 1986); e Mapeamento Educacional Urbano (Arantes, 1991). Por serem trabalhos antigos, utilizaram a cartografia analógica na elaboração dos mapas.

$\mathrm{Na}$ era da cartografia digital, diversos outros trabalhos resgataram o conceito de acessibilidade relacionado ao raio de abrangência de equipamentos urbanos. Dentre esses trabalhos, podemos citar os trabalhos de: Holanda (2006), que apresentou uma metodologia para a avaliação da acessibilidade na localização das escolas, considerando a malha viária urbana; Oliveira (2007), o qual gerou indicadores da qualidade de vida populacional em função da acessibilidade a diversos serviços públicos; Batista et al (2011), os quais realizaram um estudo com o objetivo de determinar a acessibilidade dos equipamentos educacionais utilizando a metodologia de raios de abrangência das escolas, em uma hierarquia qualitativa; Silva (2013), que realizou um estudo buscando compreender a relação entre vulnerabilidade social e localização de escolas públicas; e Neves (2015), que realizou um estudo com o objetivo de explorar os atuais métodos e critérios de planejamento urbano para implantação de equipamentos comunitários de educação e saúde.

O trabalho de Arantes (1991, p. 23) apresenta uma equação que permite calcular o raio de recrutamento de escolas de ensino fundamental, mediante a obtenção dos dados demográficos fornecidos pelo censo demográfico do Instituto Brasileiro de Geografia e Estatística (IBGE), assim como dos dados referentes ao número de matrículas do censo escolar obtidos pelo Instituto Nacional de Pesquisas Educacionais Anísio Teixeira (INEP).

Segue a equação:

$$
R=\sqrt{ } \frac{M}{\pi \times D \times p}
$$

Onde:

$\mathrm{R}$ : raio de recrutamento;

$\mathrm{M}: \mathrm{n}^{\circ}$ de matrículas;

D: densidade demográfica;

p: parâmetro de atendimento (matrículas : população). 
A cobertura territorial dos raios de recrutamento indica as áreas que, teoricamente, são atendidas e as áreas que são carentes de atendimento. Caso ocorra uma concentração espacial de equipamentos de ensino em determinada área, haverá uma superposição dos raios de recrutamento, indicando elevada oferta de creches e/ou pré-escolas naquela área. No caso contrário, as áreas muito distantes dos raios de recrutamento indicam dificuldades de acesso da população aos equipamentos de ensino, apontando a necessidade de instalações de creches e/ou pré-escolas naquela área.

\section{Materiais e Método}

Para a presente pesquisa utilizou-se dados do censo do IBGE de 2010, referentes à população de 0 a 3 anos para creches, população de 4 a 5 anos para pré-escolas e renda média do responsável pelo lar; dados do censo escolar do INEP de 2010 e 2015, referentes a matrículas em creches e matrículas em pré-escolas; malha digital dos setores censitários; malha digital com a mancha urbana do Município de Porto Alegre (Hasenack et al, 2007); malha digital das Regiões do Orçamento Participativo de Porto Alegre; e a identificação e localização das creches e pré-escolas do município. Os dados foram integrados no Arcgis 10.3 e Excel 2007, com a sistematização e compilação dos dados em mapas temáticos e tabelas. A operacionalização desses dados ocorreu em duas etapas metodológicas.

Na primeira etapa analisou-se Porto Alegre por regiões. Nesse momento foram geradas duas tabelas: a primeira representa a taxa de atendimento referente às creches por região; a segunda tabela indica o crescimento das matrículas em creches por região no período 2010 2015. Com base nessas duas tabelas foi selecionada uma região para creches e outra para pré-escolas para ser realizada uma análise espacial aprofundada, com a finalidade de identificar áreas prioritárias para a construção de equipamentos de educação infantil.

Na segunda etapa, analisou-se individualmente cada uma das regiões selecionadas. Para isso, foram gerados dois mapas para as creches e dois para as pré-escolas: o primeiro baseado na variável renda e o segundo baseado na população de crianças por faixas etárias correspondentes. 
Para a geração desses mapas, utilizou-se o método dasimétrico, através do qual foi possível gerar mapas das regiões com um maior nível de detalhamento. De acordo com Silveira e Kawakubo (2013), no método dasimétrico apenas as áreas habitadas são consideradas no cálculo da densidade demográfica. As informações relacionadas ao uso da terra são extraídas de fontes complementares e, posteriormente, são combinadas com os dados do censo demográfico por meio de técnicas de Geoprocessamento.

A Figura 1 exemplifica a diferença nos valores da distribuição espacial da população de crianças de 0 a 3 anos, dentro de um setor censitário. Na situação A da Figura 1 é representado o método coroplético, onde a população é homogeneamente distribuída dentro da área do setor, sem levar em consideração os vazios urbanos. Já na situação B da Figura 1, é representado o método dasimétrico, onde a população é heterogeneamente distribuída dentro da área do setor, levando em consideração as áreas efetivamente urbanizadas. Para realizar a distribuição espacial dentro da área do setor, é aplicada uma regra de três simples, ao se distribuir o valor da variável proporcionalmente ao tamanho do polígono inserido no setor censitário.

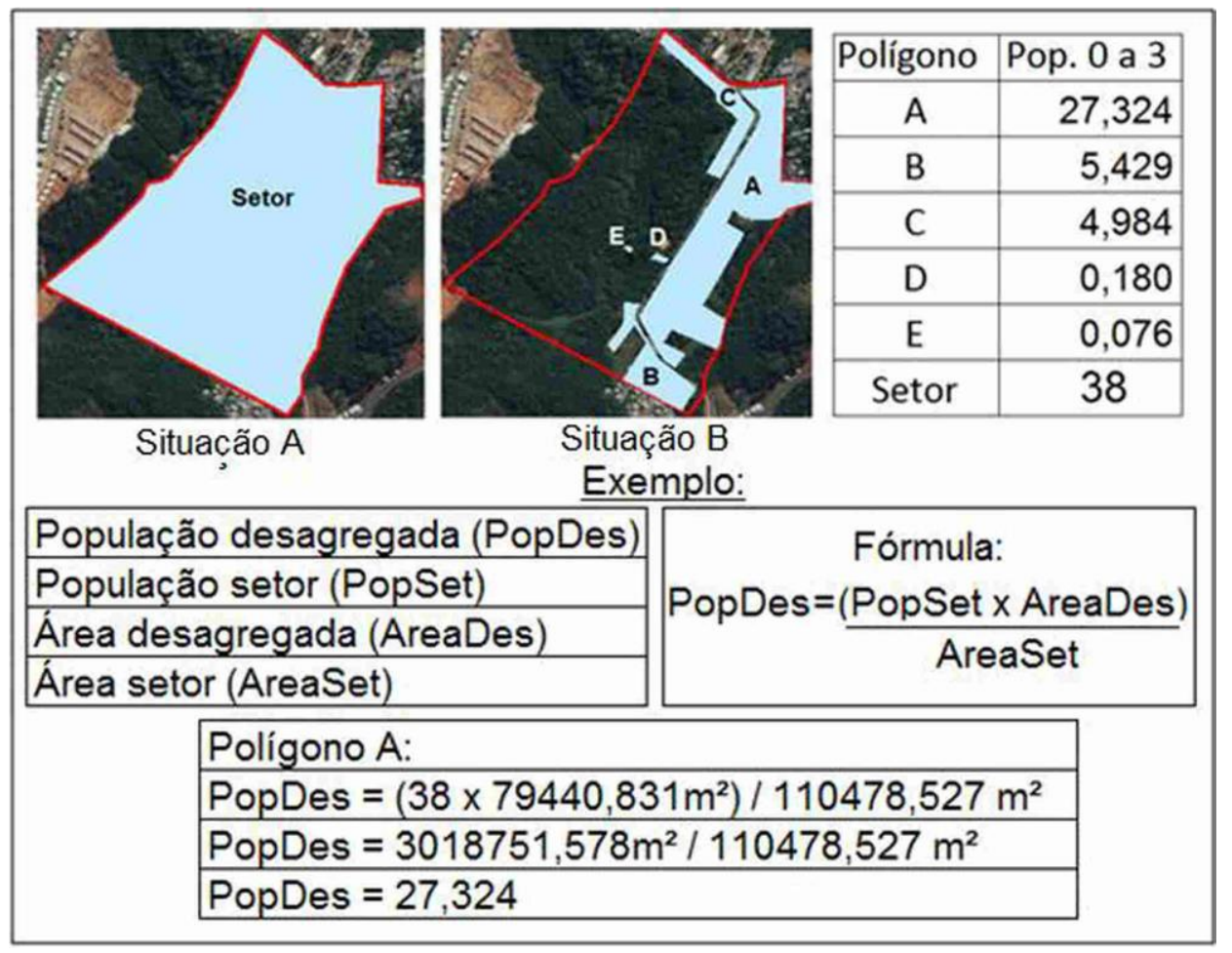

Figura 1 - Distribuição do valor total da variável do setor censitário durante a utilização do método dasimétrico. Fonte: elaborado pelo autor (2017). 
No primeiro mapa, a renda média do responsável pela moradia foi associada aos polígonos que representavam as áreas habitadas e, posteriormente, foi realizada a sua sobreposição com os pontos de localização dos equipamentos de educação infantil, agrupadas por tipo de dependência administrativa. Já no segundo mapa, as informações demográficas foram associadas às áreas poligonais e realizada a sua sobreposição com os pontos de localização dos equipamentos de educação infantil. Os equipamentos foram definidos em três grupos: em atividade em 2010 e 2015; em atividade apenas em 2010; em atividade apenas em 2015. Para cada uma das creches foi inserido um número identificador. A partir desse número, foi possível consultar uma tabela associada ao mapa e identificar o total de matrículas nos anos de 2010 e 2015 para cada um desses equipamentos.

Foi criado um raio de recrutamento para cada equipamento de educação infantil que se encontrava em atividade em 2010. O raio de recrutamento se refere à circunferência medida em metros na qual se localiza a residência dos alunos e se tem o equipamento como centro do círculo. O seu cálculo foi obtido mediante o uso da fórmula de Arantes (1991), apresentada na seção anterior.

Onde:

R: raio de recrutamento;

M: matrículas na creche ou pré-escola;

D: densidade demográfica da região;

p: matrículas da região $\div$ população da região.

Com base nos raios de recrutamento, foi possível identificar quais as áreas que possuem melhores condições de acesso aos equipamentos de ensino, assim como as áreas que apresentam carência de atendimento. Dessa forma, foi possível identificar quais são as áreas prioritárias para a construção de creches e pré-escolas. 


\section{Regiões de Porto Alegre com maior carência de equipamentos de ensino infantil}

Para fins de estudo de caso empírico, adotou-se a análise espacial de 17 regiões do município de Porto Alegre. Nessa etapa foram geradas duas tabelas: a primeira representando a taxa de atendimento em creche ou pré-escolas por região; a segunda indicando o crescimento das matrículas em creches ou pré-escolas por região no período 2010 - 2015. Com base nessas duas tabelas foi selecionada uma região para creches e outra para pré-escolas para ser realizada uma análise mais específica, com a finalidade de identificar áreas prioritárias para a construção de equipamentos de educação infantil.

\subsection{Creches}

Como o PNE vigente para o período de 2014-2024 estabelece que os municípios devem ampliar o percentual mínimo de 50\% para o atendimento de crianças de 0 a 3 anos em creches até o ano de 2024, Porto Alegre apresentou em 2010 uma taxa de atendimento de 27,96\%. Conforme a Tabela 2, apenas quatro regiões apresentaram um percentual acima da média municipal: Centro, Noroeste, Humaitá/Navegantes e Ilhas. Essas regiões correspondem a áreas mais densificadas e de ocupação mais antiga.

No outro extremo, as três regiões que apresentaram as taxas de atendimento mais baixas foram o Extremo-Sul, Cristal e Partenon, com 9,3\%, 21\% e 21,5\%, respectivamente. A Tabela 3 indica que essas três regiões apresentaram um aumento de 123\% (207 matrículas), 36\% (89 matrículas) e 7\% (85 matrículas), respectivamente, no quinquênio em análise.

Com relação à escolha da região, o Extremo-Sul apresenta características de ocupação do tipo rural, o que inviabiliza a aplicação da metodologia de raios de recrutamento. Já a região Cristal apresenta uma área territorial muito pequena, refletindo em um pequeno número de crianças de 0 a 3 anos (1191 crianças). Dessa forma, foi escolhida a região Partenon, por apresentar uma ampla área territorial, um elevado nível de ocupação urbana e ser a segunda região com mais crianças de 0 a 3 anos. Além disso, foi a região que apresentou a menor taxa de crescimento de matrículas no período 2010 - 2015. 
Tabela 2 - Taxas de atendimento das creches por região

\begin{tabular}{|r|l|r|r|r|}
\hline $\mathrm{N}^{\circ}$ & $\begin{array}{c}\text { Matrículas } \\
(2010)\end{array}$ & $\begin{array}{c}\text { População } \\
(0 \text { } 3)\end{array}$ & $\begin{array}{c}\text { Taxa de } \\
\text { atendimento }\end{array}$ \\
\hline 16 & CENTRO & 4233 & 7283 & $58,1 \%$ \\
\hline 2 & NOROESTE & 2279 & 4143 & $55,0 \%$ \\
\hline 1 & HUMAITÁ/NAVEGANTES & 181 & 2291 & $34,7 \%$ \\
\hline 17 & ILHAS & 1233 & 4602 & $33,6 \%$ \\
\hline 14 & EIXO BALTAZAR & 1292 & 4959 & $26,8 \%$ \\
\hline 12 & CENTRO SUL & 1330 & 5291 & $25,1 \%$ \\
\hline 3 & LESTE & 883 & 3553 & $24,9 \%$ \\
\hline 10 & CRUZEIRO & 1216 & 4881 & $24,9 \%$ \\
\hline 5 & NORTE & 921 & 3942 & $23,4 \%$ \\
\hline 8 & RESTINGA & 859 & 3667 & $23,4 \%$ \\
\hline 15 & SUL & 571 & 2460 & $23,2 \%$ \\
\hline 6 & NORDESTE & 516 & 2265 & $22,8 \%$ \\
\hline 9 & GLÓRIA & 899 & 4160 & $21,6 \%$ \\
\hline 4 & LOMBA DO PINHEIRO & 1224 & 5697 & $21,5 \%$ \\
\hline 7 & PARTENON & 250 & 1191 & $21,0 \%$ \\
\hline 11 & CRISTAL & 168 & 1808 & $9,3 \%$ \\
\hline 13 & EXTREMO SUL & & & \\
\hline
\end{tabular}

Fonte: Elaborado pelo autor (2017) com dados do INEP (2010) e IBGE (2010).

Tabela 3 - Crescimento das matrículas em creches por região no período 2010 - 2015.

\begin{tabular}{|l|l|r|r|r|r|}
\hline$N^{\circ}$ & $\begin{array}{c}\text { Megião } \\
(2010)\end{array}$ & 168 & $\begin{array}{c}\text { Matrículas } \\
(2015)\end{array}$ & $\begin{array}{l}\text { Matrículas } \\
\text { (Cresc.) }\end{array}$ & $\%$ \\
\hline 13 & EXTREMO SUL & 859 & 1380 & 207 & $123 \%$ \\
\hline 15 & SUL & 1216 & 1806 & 521 & $61 \%$ \\
\hline 5 & NORTE & 181 & 270 & 89 & $49 \%$ \\
\hline 17 & ILHAS & 899 & 1305 & 406 & $45 \%$ \\
\hline 4 & LOMBA DO PINHEIRO & 1233 & 1714 & 481 & $39 \%$ \\
\hline 14 & EIXO BALTAZAR & 921 & 1269 & 348 & $38 \%$ \\
\hline 8 & RESTINGA & 250 & 339 & 89 & $36 \%$ \\
\hline 11 & CRISTAL & 883 & 1174 & 291 & $33 \%$ \\
\hline 10 & CRUZEIRO & 2279 & 3010 & 731 & $32 \%$ \\
\hline 2 & NOROESTE & 571 & 742 & 171 & $30 \%$ \\
\hline 6 & NORDESTE & 1330 & 1716 & 386 & $29 \%$ \\
\hline 3 & LESTE & 1292 & 1653 & 361 & $28 \%$ \\
\hline 12 & CENTRO SUL & 796 & 972 & 176 & $22 \%$ \\
\hline 1 & HUMAITÁ/NAVEGANTES & 4233 & 5130 & 897 & $21 \%$ \\
\hline 16 & CENTRO & 516 & 586 & 70 & $14 \%$ \\
\hline 9 & GLÓRIA & 1224 & 1309 & 85 & $7 \%$ \\
\hline 7 & PARTENON & & &
\end{tabular}

Fonte: elaborado pelo autor (2017) com dados do INEP (2010 e 2015). 


\subsection{Pré-escolas}

O PNE (2014-2024) estabelece a universalização do acesso à pré-escola para a população de 4 a 5 anos até 2024. Nesse quesito, Porto Alegre apresentou uma taxa de atendimento de 61,01\% já em 2010. Portanto, para a faixa etária das crianças em idade pré-escolar, o município tem grandes perspectivas de atingir a universalização de acesso até 2024.

Conforme a Tabela 4, apenas cinco regiões apresentaram taxas acima da média municipal, inclusive com taxas de atendimento que suplantaram as necessidades da população alvo, como nas regiões Centro e Noroeste.

Em contrapartida, o Extremo-Sul (27\%), a Lomba do Pinheiro (34\%) e o Nordeste (36\%) apresentaram as taxas mais baixas de Porto Alegre. De acordo com a Tabela 5, essas três regiões apresentaram taxas de crescimento similares e bastante significativas no quinquênio 2010 - 2015, com 40\% (105 matrículas), 39\% (278 matrículas) e 39\% (175 matrículas), respectivamente.

Tabela 4 - Taxas de atendimento das pré-escolas por região

\begin{tabular}{|c|c|c|c|c|}
\hline$N^{\circ}$ & Região & $\begin{array}{c}\text { Matrículas } \\
\text { (2010) }\end{array}$ & $\begin{array}{c}\text { População } \\
\text { (4 a 5) }\end{array}$ & $\begin{array}{c}\text { Taxa de } \\
\text { atendimento }\end{array}$ \\
\hline 16 & CENTRO & 4368 & 3414 & $127,9 \%$ \\
\hline 2 & NOROESTE & 2508 & 2041 & $122,9 \%$ \\
\hline 1 & HUMAITÁ/NAVEGANTES & 860 & 1191 & $72,2 \%$ \\
\hline 3 & LESTE & 1839 & 2773 & $66,3 \%$ \\
\hline 12 & CENTRO SUL & 1599 & 2574 & $62,1 \%$ \\
\hline 15 & SUL & 1136 & 1882 & $60,3 \%$ \\
\hline 7 & PARTENON & 1733 & 2943 & $58,9 \%$ \\
\hline 5 & NORTE & 1537 & 2615 & $58,8 \%$ \\
\hline 14 & EIXO BALTAZAR & 1333 & 2297 & $58,0 \%$ \\
\hline 9 & GLÓRIA & 697 & 1256 & $55,5 \%$ \\
\hline 8 & RESTINGA & 1057 & 2012 & $52,5 \%$ \\
\hline 10 & CRUZEIRO & 973 & 1927 & $50,5 \%$ \\
\hline 17 & ILHAS & 147 & 302 & $48,7 \%$ \\
\hline 11 & CRISTAL & 271 & 592 & $45,8 \%$ \\
\hline 6 & NORDESTE & 454 & 1261 & $36,0 \%$ \\
\hline 4 & LOMBA DO PINHEIRO & 720 & 2109 & $34,1 \%$ \\
\hline 13 & EXTREMO SUL & 262 & 983 & $26,6 \%$ \\
\hline
\end{tabular}

Fonte: elaborado pelo autor (2017) com dados do INEP (2010) e IBGE (2010). 
Tabela 5 - Crescimento das matrículas em pré-escolas por região no período 2010 - 2015

\begin{tabular}{|r|l|r|r|r|}
\hline \multicolumn{1}{|c|}{$\mathrm{N}^{\circ}$} & Região & $\begin{array}{c}\text { Matrículas } \\
(2010)\end{array}$ & $\begin{array}{c}\text { Matrículas } \\
(2015)\end{array}$ & Crescimento \\
\hline 17 & ILHAS & 147 & 235 & $60 \%$ \\
\hline 15 & SUL & 1136 & 1611 & $42 \%$ \\
\hline 13 & EXTREMO SUL & 262 & 367 & $40 \%$ \\
\hline 4 & LOMBA DO PINHEIRO & 720 & 998 & $39 \%$ \\
\hline 6 & NORDESTE & 454 & 629 & $39 \%$ \\
\hline 2 & NOROESTE & 2508 & 3073 & $23 \%$ \\
\hline 8 & RESTINGA & 1057 & 1287 & $22 \%$ \\
\hline 14 & EIXO BALTAZAR & 1333 & 1616 & $21 \%$ \\
\hline 5 & NORTE & 1537 & 1837 & $20 \%$ \\
\hline 9 & GLÓRIA & 697 & 794 & $14 \%$ \\
\hline 12 & CENTRO SUL & 1599 & 1771 & $11 \%$ \\
\hline 10 & CRUZEIRO & 973 & 1068 & $10 \%$ \\
\hline 16 & CENTRO & 4368 & 4794 & $10 \%$ \\
\hline 7 & PARTENON & 1733 & 1885 & $9 \%$ \\
\hline 11 & CRISTAL & 271 & 295 & $9 \%$ \\
\hline 1 & HUMAITÁ/NAVEGANTES & 860 & 844 & $-2 \%$ \\
\hline 3 & LESTE & 1839 & 1789 & $-3 \%$ \\
\hline
\end{tabular}

Fonte: elaborado pelo autor (2017) com dados do INEP (2010 e 2015).

Por fim, das três regiões com as piores taxas de atendimento do Município, tanto a Lomba do Pinheiro como a região Nordeste poderiam ser escolhidas para serem realizadas as análises da etapa seguinte, mas como neste trabalho se definiu a escolha de apenas uma região, optou-se por selecionar a região Lomba do Pinheiro, tendo em vista que ela possui um maior número de crianças de 4 a 5 anos.

\section{Identificação das áreas carentes de equipamentos de ensino infantil}

Nesta etapa analisou-se individualmente cada uma das regiões selecionadas. Para isso, foram gerados dois mapas para as creches e dois mapas para as pré-escolas, a partir dos quais foram realizadas as análises espaciais. 


\subsection{Região Partenon}

A partir do mapa da Figura 2 pode-se constatar que há uma tendência das creches comunitárias se localizarem nas áreas onde a renda familiar é mais baixa. Das 13 creches comunitárias, oito estão localizadas em áreas consideradas de renda baixa ou muito baixa, com destaque para a porção sudeste, a mais pobre da região, onde há a concentração de cinco creches comunitárias. Por outro lado, das 18 creches particulares, apenas quatro estão localizadas em áreas de renda baixa ou muito baixa, 11 em áreas de renda alta ou muito alta e três em área de renda intermediária. Na região também estavam em atividade cinco creches municipais, uma estadual e cinco filantrópicas, no entanto, não é possível afirmar-se que a localização dessas creches esteja diretamente vinculada à renda média das famílias do seu entorno.

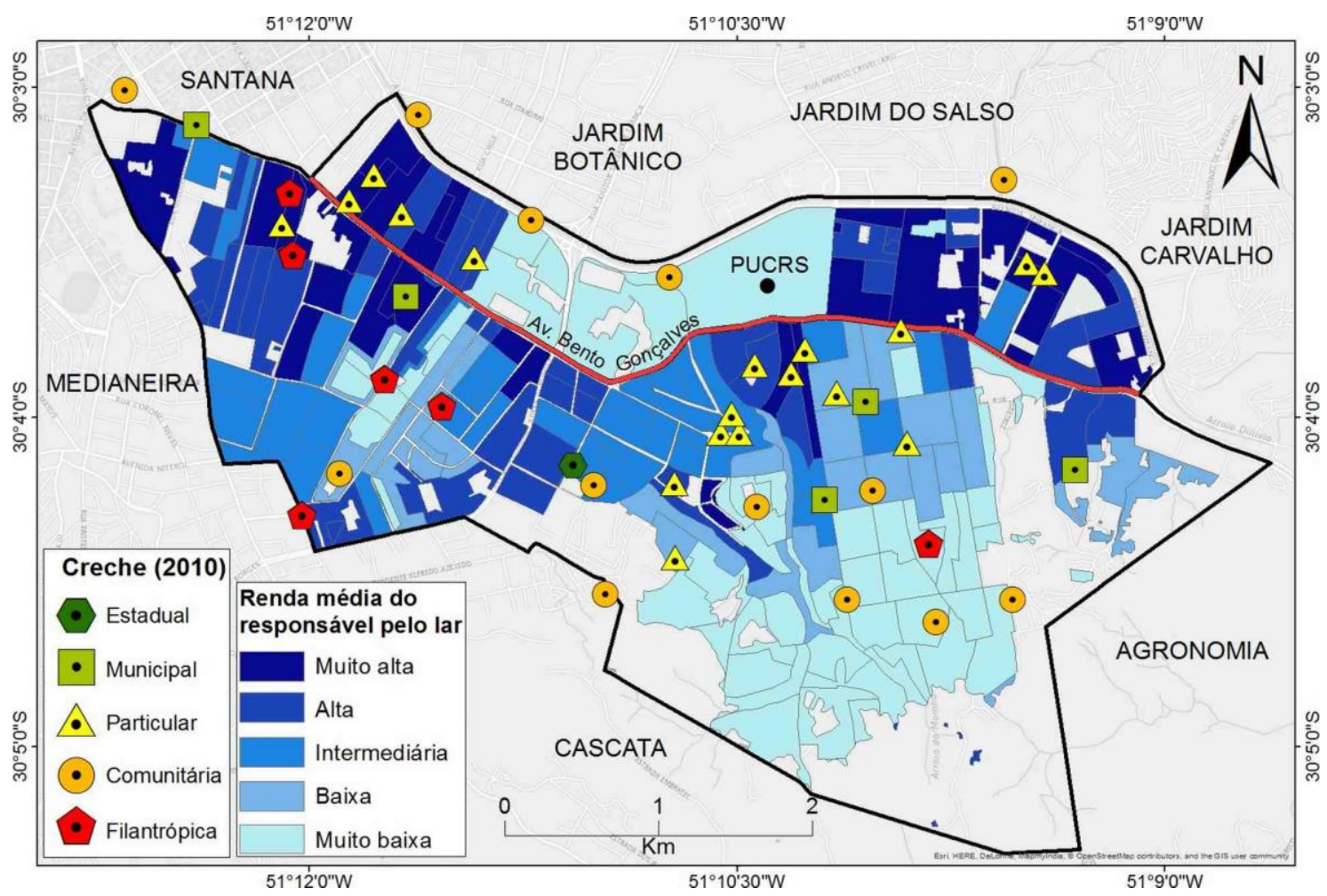

Figura 2 - Mapa de renda média dos responsáveis pelo lar e localização das creches por tipo de dependência administrativa na região Partenon.

Fonte: elaborado pelo autor (2017) com dados do IBGE (2010) e INEP (2010).

Com relação ao mapa da Figura 3 e a Tabela 6 correspondente, pode-se observar que no período 2010 - 2015 houve um aumento de apenas duas creches na região. Embora tenha ocorrido a construção de cinco creches novas (duas particulares, duas filantrópicas e uma 
comunitária), no período ocorreu também a paralisação das atividades de uma creche (particular) e a extinção de duas (particular e filantrópica). Esse pequeno aumento no número total de creches contribuiu diretamente para o aumento de apenas 85 matrículas na região. Tendo em vista o elevado número de crianças de 0 a 3 anos na região, assim como a reduzida taxa de atendimento dessas crianças em creches, constatou-se que há uma forte demanda por matrículas em creches na região Partenon. Com base nessa constatação, foi realizado o apontamento das áreas onde ocorrem as maiores demandas manifestas por esse serviço na região.

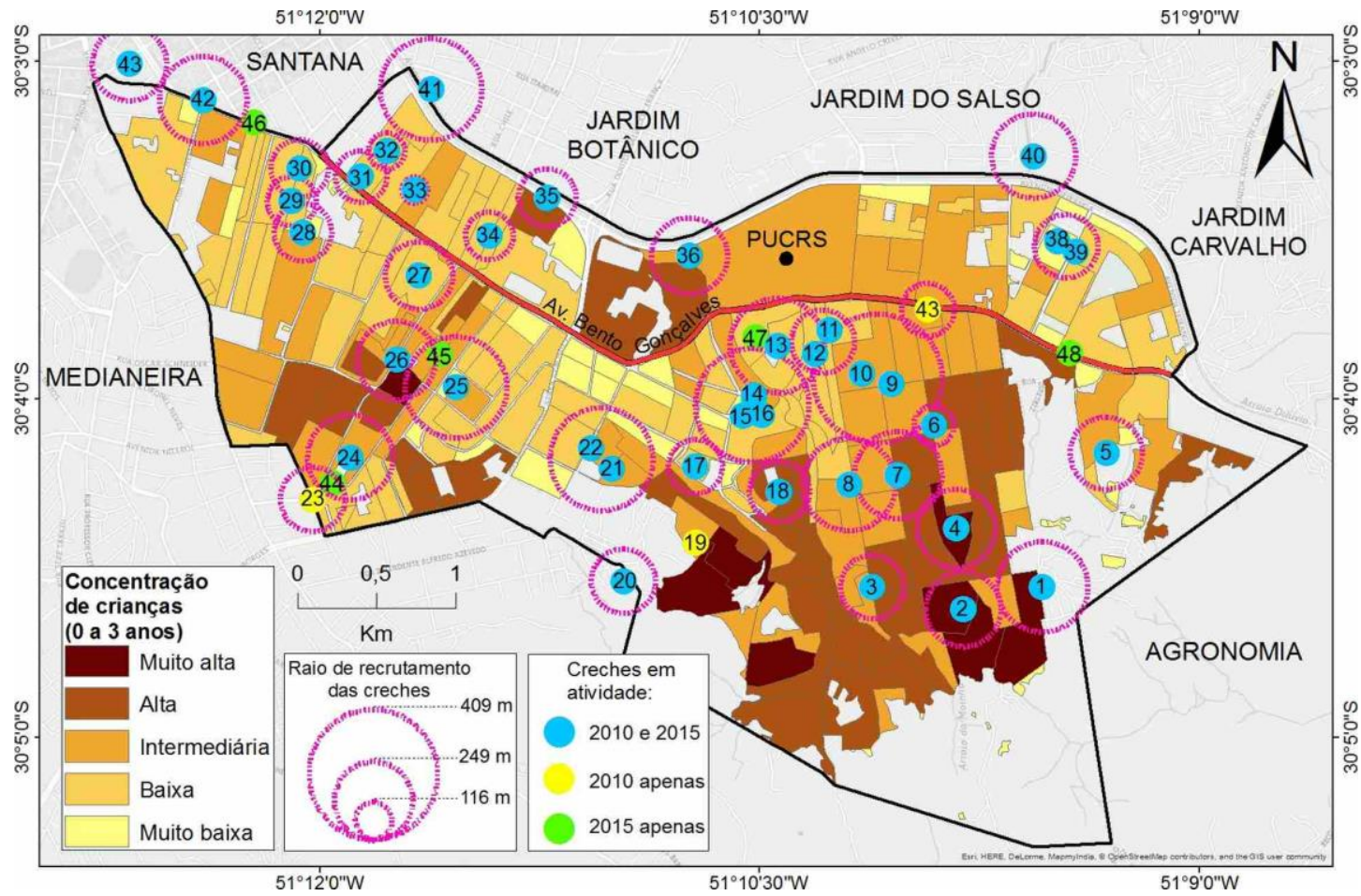

Figura 3 - Mapa de concentração de crianças de 0 a 3 anos e localização das creches nos anos de 2010 e 2015 com o raio de recrutamento para as creches de 2010 na região Partenon. Fonte: elaborado pelo autor (2017) com dados do IBGE (2010) e INEP (2010 e 2015).

Pode-se afirmar que a maior presença de creches não coincide necessariamente com as áreas onde há a maior concentração de crianças de 0 a 3 anos. A maior incidência de creches está localizada na porção centro-leste do mapa, assim como na porção noroeste. Essa maior concentração de creches nessas áreas é devido à grande presença de equipamentos particulares. 
Tabela 6 - Total de creches em 2010 e 2015 com o respectivo número de matrículas e dependência administrativa desses equipamentos na região Partenon.

\begin{tabular}{|c|c|c|c|c|c|c|c|c|c|c|c|}
\hline $\mathrm{N}^{\circ}$ & Dep.adm. & Mat. & $\mathrm{N}^{\circ}$ & Dep.adm. & Mat. & $\mathrm{N}^{\circ}$ & Dep.adm. & Mat. & $\mathrm{N}^{\circ}$ & Dep.adm. & Mat. \\
\hline \multicolumn{6}{|c|}{2010} & \multicolumn{6}{|c|}{2015} \\
\hline 1 & Comunitária & 61 & 23 & Filantrópica & 31 & 1 & Comunitária & 64 & 25 & Filantrópica & 26 \\
\hline 2 & Comunitária & 42 & 24 & Comunitária & 54 & 2 & Comunitária & 71 & 26 & Filantrópica & 0 \\
\hline 3 & Comunitária & 30 & 25 & Filantrópica & 77 & 3 & Comunitária & 62 & 27 & Municipal & 20 \\
\hline 4 & Filantrópica & 46 & 26 & Filantrópica & 46 & 4 & Filantrópica & 42 & 28 & Filantrópica & 37 \\
\hline 5 & Municipal & 39 & 27 & Municipal & 34 & 5 & Municipal & 40 & 29 & Particular & 12 \\
\hline 6 & Particular & 12 & 28 & Filantrópica & 25 & 6 & Particular & 0 & 30 & Filantrópica & 32 \\
\hline 7 & Comunitária & 57 & 29 & Particular & 18 & 7 & Comunitária & 54 & 31 & Particular & 55 \\
\hline 8 & Municipal & 64 & 30 & Filantrópica & 25 & 8 & Municipal & 59 & 32 & Particular & 21 \\
\hline 9 & Municipal & 60 & 31 & Particular & 20 & 9 & Municipal & 57 & 33 & Particular & 0 \\
\hline 10 & Particular & 14 & 32 & Particular & 10 & 10 & Particular & 54 & 34 & Particular & 4 \\
\hline 11 & Particular & 16 & 33 & Particular & 5 & 11 & Particular & 25 & 35 & Comunitária & 34 \\
\hline 12 & Particular & 28 & 34 & Particular & 17 & 12 & Particular & 19 & 36 & Comunitária & 58 \\
\hline 13 & Particular & 67 & 35 & Comunitária & 25 & 13 & Particular & 78 & 37 & \multicolumn{2}{|l|}{ Extinta } \\
\hline 14 & Particular & 18 & 36 & Comunitária & 43 & 14 & Particular & 19 & 38 & Particular & 11 \\
\hline 15 & Particular & 11 & 37 & Particular & 21 & 15 & Particular & 0 & 39 & Particular & 23 \\
\hline 16 & Particular & 17 & 38 & Particular & 21 & 16 & Particular & 14 & 40 & Comunitária & 60 \\
\hline 17 & Particular & 22 & 39 & Particular & 21 & 17 & Particular & 25 & 41 & Comunitária & 59 \\
\hline 18 & Comunitária & 27 & 40 & Comunitária & 53 & 18 & Comunitária & 26 & 42 & Municipal & 50 \\
\hline 19 & Particular & 2 & 41 & Comunitária & 77 & 19 & \multicolumn{2}{|c|}{ Paralisada } & 43 & Comunitária & 44 \\
\hline 20 & Comunitária & 31 & 42 & Municipal & 57 & 20 & Comunitária & 32 & 44 & Particular & 19 \\
\hline 21 & Comunitária & 48 & 43 & Comunitária & 41 & 21 & Comunitária & 55 & 45 & Comunitária & 63 \\
\hline 22 & Estadual & 41 & \multicolumn{3}{|c|}{-} & 22 & Estadual & 16 & 46 & Particular & 27 \\
\hline & & & & & & 23 & \multicolumn{2}{|c|}{ Extinta } & 47 & Filantrópica & 29 \\
\hline & & & & & & 24 & Comunitária & 58 & 48 & Filantrópica & 27 \\
\hline
\end{tabular}

Fonte: elaborado pelo autor (2017) com dados do INEP (2010 e 2015).

Por outro lado, na porção sudeste, onde ocorre a maior concentração de crianças de 0 a 3 anos da região, é também onde ocorre uma das maiores carências de atendimento registradas no mapa. Essa porção coincide justamente com as áreas de maior concentração de pobreza, apontadas pelo mapa da Figura 2. Como se pode constatar, esta porção do mapa é atendida diretamente pelas creches $n^{\circ}: 1,2,3$ e 4, assim como pelas creches $n^{\circ} 7,8$ e 18 , embora estas se situem um pouco mais distantes da área central da porção sudeste. Mediante consulta na Tabela 6, ao se comparar o total de matrículas dessas creches no período 2010 - 2015 observou-se que as creches $n^{\circ} 1$, 2 e 3 contabilizaram juntas no período 
um expressivo aumento de 64 matrículas a mais. Já as creches $n^{\circ} 4,7,8$ e 18 apresentaram perdas de matrículas, porém pouco significativas, contabilizando um total de 13 matrículas a menos no período. Essas análises nos levam a deduzir que essas creches se encontram em seus limites de atendimento.

A fim de qualificar melhor a porção sudeste e identificar as áreas prioritárias para a construção de creches, foi elaborado o mapa da Figura 4, fruto da análise conjunta entre os mapas das Figuras 2 e 3 . A definição dos limites da porção sudoeste em análise foi feita com base na sobreposição das áreas de renda muito baixa do mapa da Figura 2, com as áreas de maior concentração de crianças de 0 a 3 anos, no mapa da Figura 3.

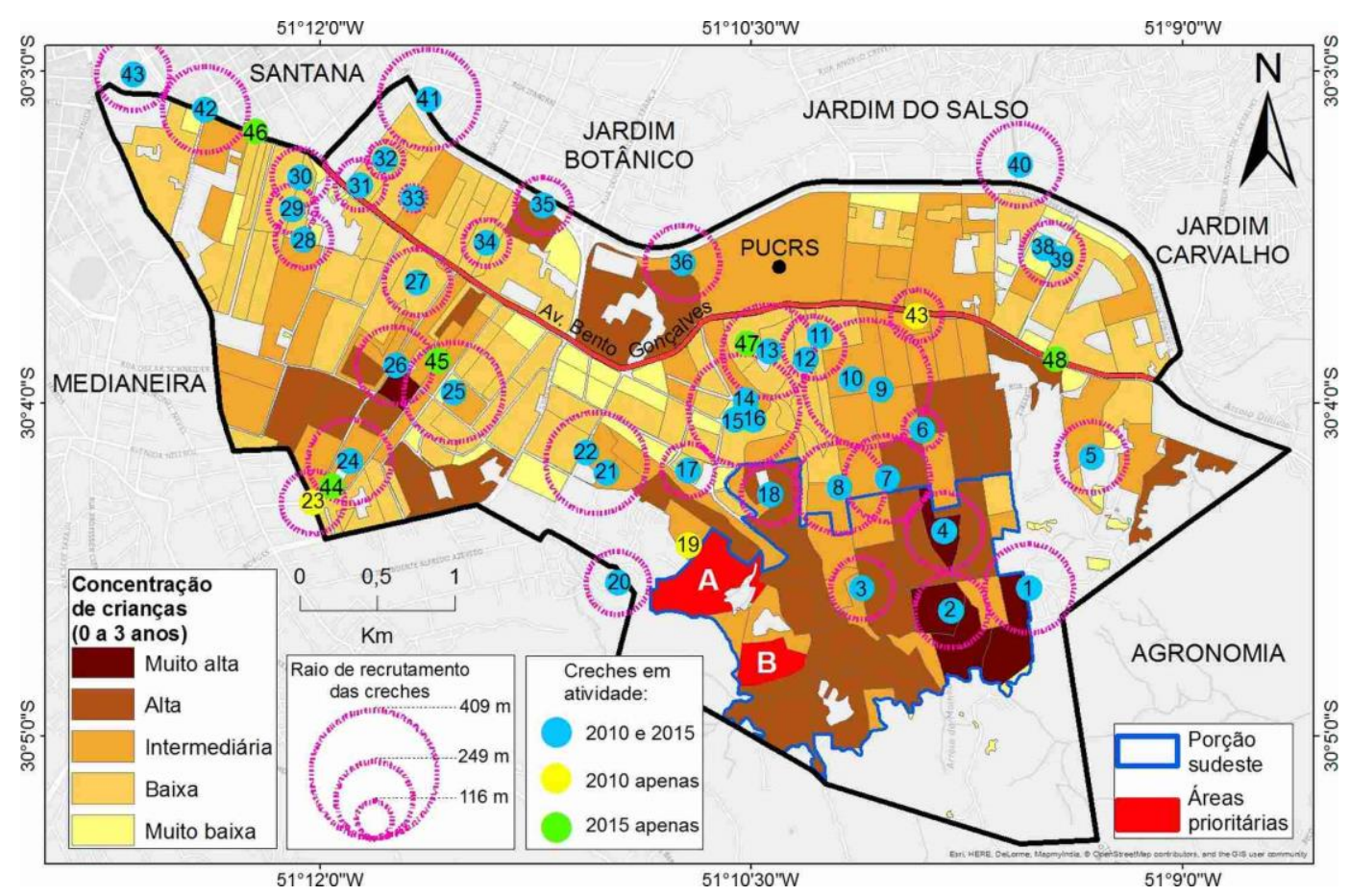

Figura 4 - Mapa de identificação das áreas prioritárias para a instalação de creches na região Partenon

Fonte: elaborado pelo autor (2017) com dados do IBGE (2010) e INEP (2010 e 2015).

Como se pode constatar no mapa da Figura 4, os limites da porção sudoeste foram delimitados pelas linhas em azul. Dentro dos limites dessa porção, a população de 0 a 3 anos é estimada em torno de 2000 crianças. Com relação ao total de matrículas, foram consideradas apenas as creches $n^{\circ} 1,2,3,4,7,8$ e 18. Em 2010, essas creches representavam um total de 327 matrículas, enquanto em 2015 esse número era de 381 matrículas. 
Diante da constatação desse déficit de matrículas, a seleção das áreas prioritárias para a construção de creches ocorreu no interior da porção sudeste da região. Essas áreas encontram-se preenchidas em vermelho, conforme se pode observar no mapa da Figura 4.

Nesse sentido, foram definidas duas áreas com uma concentração muito alta de crianças de 0 a 3 anos. A área " $A$ " possui um total de aproximadamente 178 crianças e o centro de gravidade dessa área se encontra a uma distância de aproximadamente 650 metros da creche mais próxima ( $\left.n^{\circ} 18\right)$. Ressalta-se que apesar de esta área estar próxima à creche $n^{\circ} 19, a$ instituição é particular e se encontrava fechada em 2015. Já a área "B" possui um total de aproximadamente 73 crianças de 0 a 3 anos e o seu centro de gravidade se encontra a uma distância de aproximadamente 750 metros da creche mais próxima $\left(n^{\circ} 3\right)$.

\subsection{Região Lomba do Pinheiro}

Ao analisar-se o mapa da Figura 5, observa-se a existência de três concentrações urbanas de maior porte na região, separadas do resto da cidade por vazios urbanos. A primeira porção no setor nordeste, cortada pela Rua Dolores Duran. A segunda porção a oeste sendo seccionada pela Estrada Afonso Lourenço Mariante. E a terceira porção no sudeste, ao longo da Estrada João de Oliveira Remião e fazendo divisa com o Município de Viamão. Destaca-se que o eixo de ligação entre essas três concentrações urbanas com o restante da cidade ocorre através da Estrada João de Oliveira Remião, a qual corta a região de norte a sul. Entre essas três porções regionais é possível constatar que não há uma grande diferenciação de renda entre elas, tendo em vista a ausência de áreas de renda muito alta, assim como a grande concentração de áreas de renda baixa e intermediárias nessas três porções. 


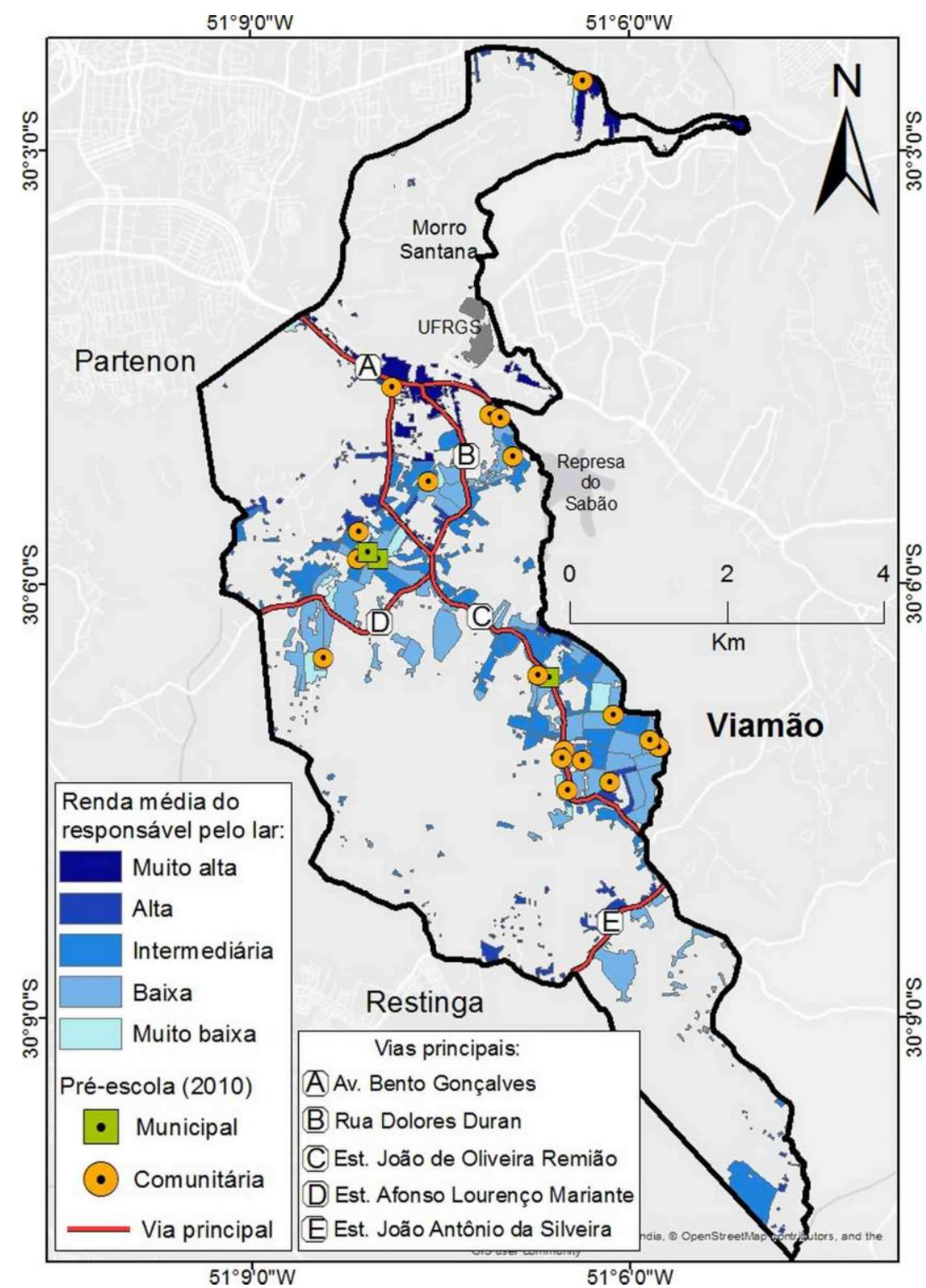

Figura 5 - Mapa de renda média dos responsáveis pelo lar e localização das pré-escolas por tipo de dependência administrativa na região Lomba do Pinheiro.

Fonte: elaborado pelo autor (2017) com dados do IBGE (2010) e INEP (2010).

O mapa da Figura 6 ilustra a distribuição espacial das crianças de 4 a 5 anos, assim como a distribuição das pré-escolas existentes em 2010 e 2015 na região Lomba do Pinheiro. Os equipamentos que se encontravam em funcionamento em 2010 e 2015 estão representados pela cor azul, os que se encontravam em funcionamento apenas em 2010 na cor amarela e os que se encontravam em funcionamento apenas em 2015 estão representados na cor verde. A Tabela 7 complementa as informações do referido mapa ao apresentar o total de matrículas nas pré-escolas nos anos de 2010 e 2015, assim como o tipo de dependência administrativa desses equipamentos. 


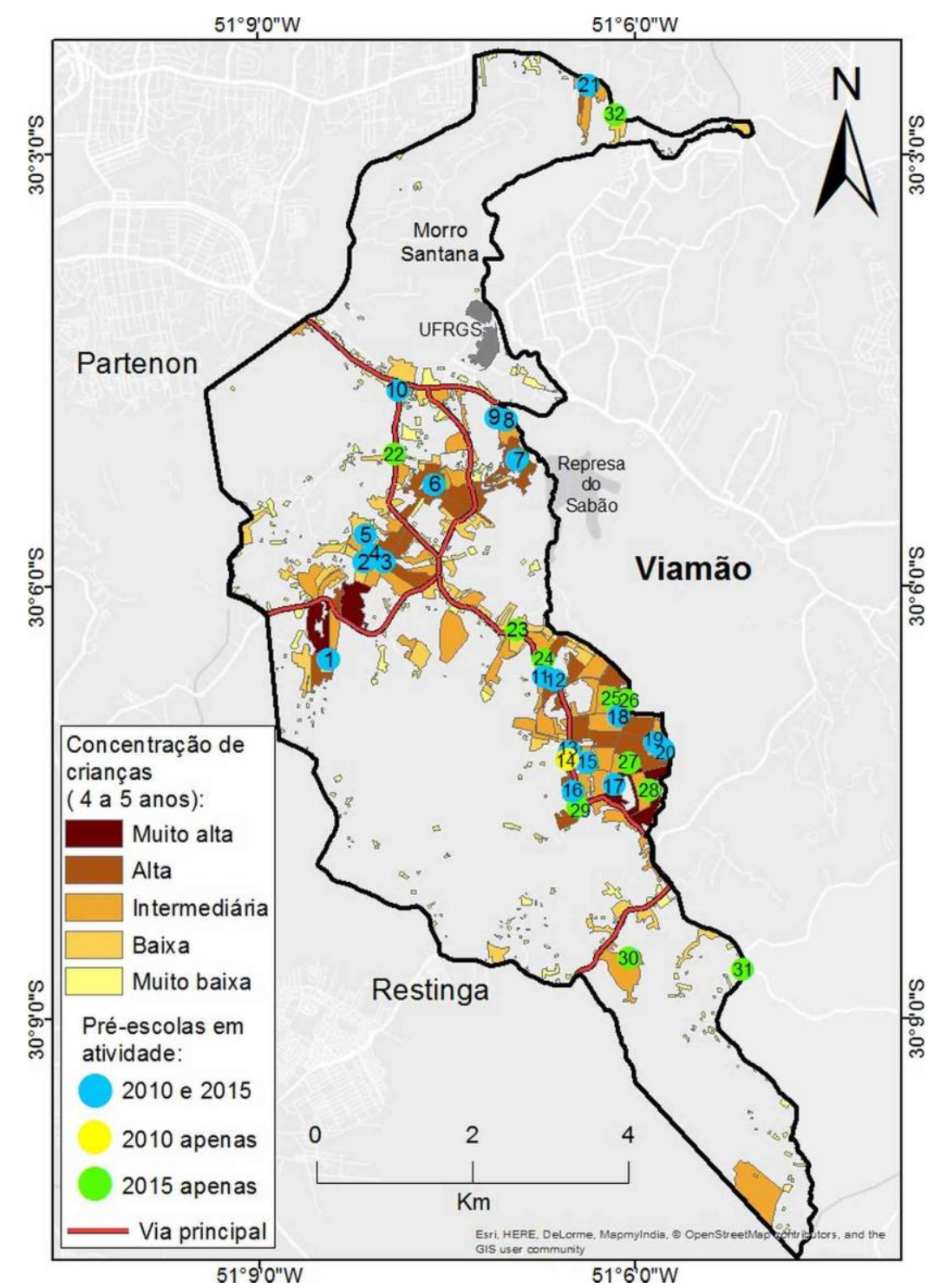

Figura 6 - Mapa de concentração de crianças de 4 a 5 anos e localização das pré-escolas nos anos de 2010 e 2015 na região Lomba do Pinheiro.

Fonte: elaborado pelo autor (2017) com dados do IBGE (2010) e INEP (2010 e 2015).

O mapa da Figura 6 e a sua correspondente Tabela 7 indicam que das 21 pré-escolas existentes em 2010 na região Lomba do Pinheiro, 18 eram comunitárias e três municipais. Já em 2015, houve a implantação de duas pré-escolas municipais, duas comunitárias, seis particulares e a desativação de uma comunitária.

Para as porções nordeste, oeste e sudeste foram gerados os mapas das Figuras 7, 8 e 9 respectivamente. Todas as porções foram delimitadas pelas linhas em azul, a fim de se extrair os dados populacionais das áreas inseridas dentro desses limites. 
Tabela 7 - Total de pré-escolas em 2010 e 2015 com o respectivo número de matrículas e dependência administrativa desses equipamentos na região Lomba do Pinheiro.

\begin{tabular}{|c|c|c|c|c|c|c|c|c|}
\hline $\mathbf{N}^{\circ}$ & Mat. & Dep. adm. & $\mathbf{N}^{\circ}$ & Mat. & Dep. adm. & $\mathbf{N}^{\circ}$ & Mat. & Dep. adm. \\
\hline \multicolumn{6}{|c|}{2010} & \multicolumn{3}{|c|}{2015} \\
\hline 1 & 53 & Comunitária & 1 & 42 & Comunitária & 22 & 13 & Particular \\
\hline 2 & 20 & Comunitária & 2 & 48 & Comunitária & 23 & 36 & Particular \\
\hline 3 & 45 & Municipal & 3 & 43 & Municipal & 24 & 11 & Particular \\
\hline 4 & 50 & Municipal & 4 & 48 & Municipal & 25 & 22 & Particular \\
\hline 5 & 35 & Comunitária & 5 & 35 & Comunitária & 26 & 49 & Municipal \\
\hline 6 & 24 & Comunitária & 6 & 22 & Comunitária & 27 & 9 & Particular \\
\hline 7 & 16 & Comunitária & 7 & 17 & Comunitária & 28 & 48 & Municipal \\
\hline 8 & 41 & Comunitária & 8 & 45 & Comunitária & 29 & 36 & Comunitária \\
\hline 9 & 47 & Comunitária & 9 & 48 & Comunitária & 30 & 19 & Comunitária \\
\hline 10 & 30 & Comunitária & 10 & 44 & Comunitária & 31 & 7 & Estadual \\
\hline 11 & 31 & Comunitária & 11 & 48 & Comunitária & 32 & 13 & Particular \\
\hline 12 & 50 & Municipal & 12 & 50 & Municipal & & & - \\
\hline 13 & 23 & Comunitária & 13 & 47 & Comunitária & & & - \\
\hline 14 & 18 & Comunitária & 14 & \multicolumn{2}{|c|}{ Desativada } & & & - \\
\hline 15 & 31 & Comunitária & 15 & 26 & Comunitária & & & - \\
\hline 16 & 24 & Comunitária & 16 & 31 & Comunitária & & & - \\
\hline 17 & 41 & Comunitária & 17 & 24 & Comunitária & & & - \\
\hline 18 & 25 & Comunitária & 18 & 22 & Comunitária & & & - \\
\hline 19 & 33 & Comunitária & 19 & 37 & Comunitária & & & - \\
\hline 20 & 38 & Comunitária & 20 & 27 & Comunitária & & & - \\
\hline 21 & 45 & Comunitária & 21 & 31 & Comunitária & & & - \\
\hline
\end{tabular}

Em 2010, a porção sudeste apresentava um total de 128 matrículas, o que representa uma taxa de atendimento de 49,8\% para aquele ano. Em 2015, o número de matrículas se manteve bastante estável, pois contabilizou-se um total de 132 matrículas. Com relação ao mapa da Figura 7, no período 2010 - 2015 não houve a implantação de pré-escolas nessa porção da Lomba do Pinheiro, a qual possui quatro estabelecimentos (nos 6, 7, 8 e 9), todos de caráter comunitário. Esses quatro equipamentos apresentaram um número de matrículas bastante estável no período. Destaca-se uma carência de atendimento no setor central dessa porção, em ambos os lados da Rua Dolores Duran, em áreas com alta concentração de crianças de 4 a 5 anos. 


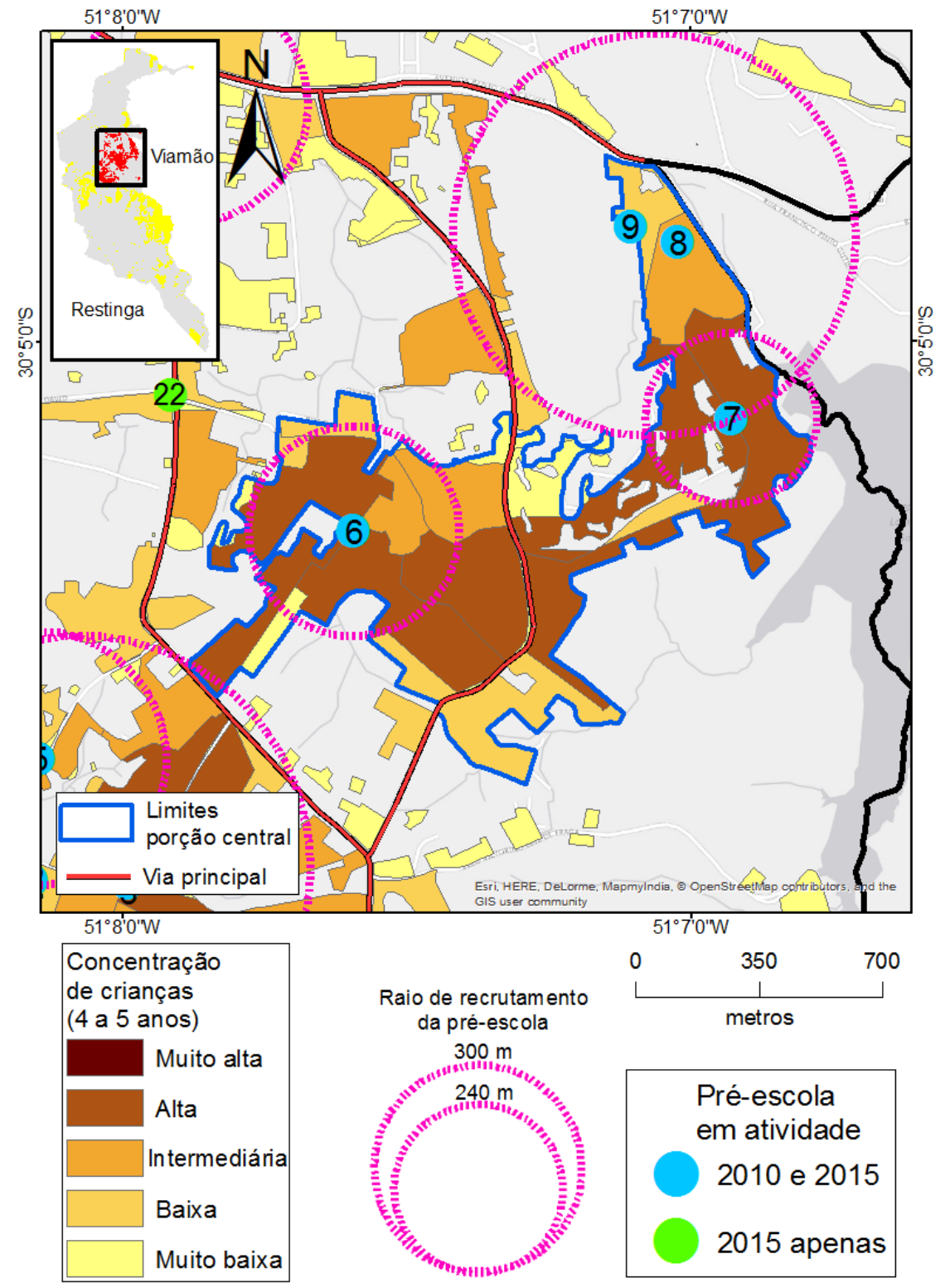

Figura 7 - Mapa de concentração de crianças de 4 a 5 anos e localização das pré-escolas nos anos de 2010 e 2015 com o raio de recrutamento das pré-escolas de 2010 na porção nordeste da região Lomba do Pinheiro.

Fonte: elaborado pelo autor (2017) com dados do IBGE (2010) e INEP (2010 e 2015).

Já a porção oeste da Lomba do Pinheiro, em 2010, apresentava um total de 203 matrículas, o que nos indica uma taxa de atendimento de 40,3\% nesse ano. Em 2015, o número de matrículas se manteve relativamente estável, pois se contabilizou um total de 216 matrículas. De acordo com o mapa da Figura 8, no período 2010 - 2015 não houve a implantação de novas pré-escolas nessa porção, a qual conta com cinco estabelecimentos (nos 1, 2, 3, 4 e 5), sendo três comunitárias e duas municipais. Embora no período em análise o número de matrículas desses equipamentos tenha se mostrado relativamente estável, as variações mais 
significativas ocorreram na pré-escola $n^{\circ} 1$, a qual apresentou uma redução de 11 matrículas, e a pré-escola $\mathrm{n}^{\circ} 2$, com o aumento de 28 matrículas. Podemos perceber que as áreas de concentração mais alta de crianças de 4 a 5 anos de idade não são as que estão necessariamente mais próximas das pré-escolas. Essas duas áreas estão representadas pela cor marrom na legenda da Figura 8 e estão localizadas nas imediações da Estrada Afonso Lourenço Mariante.

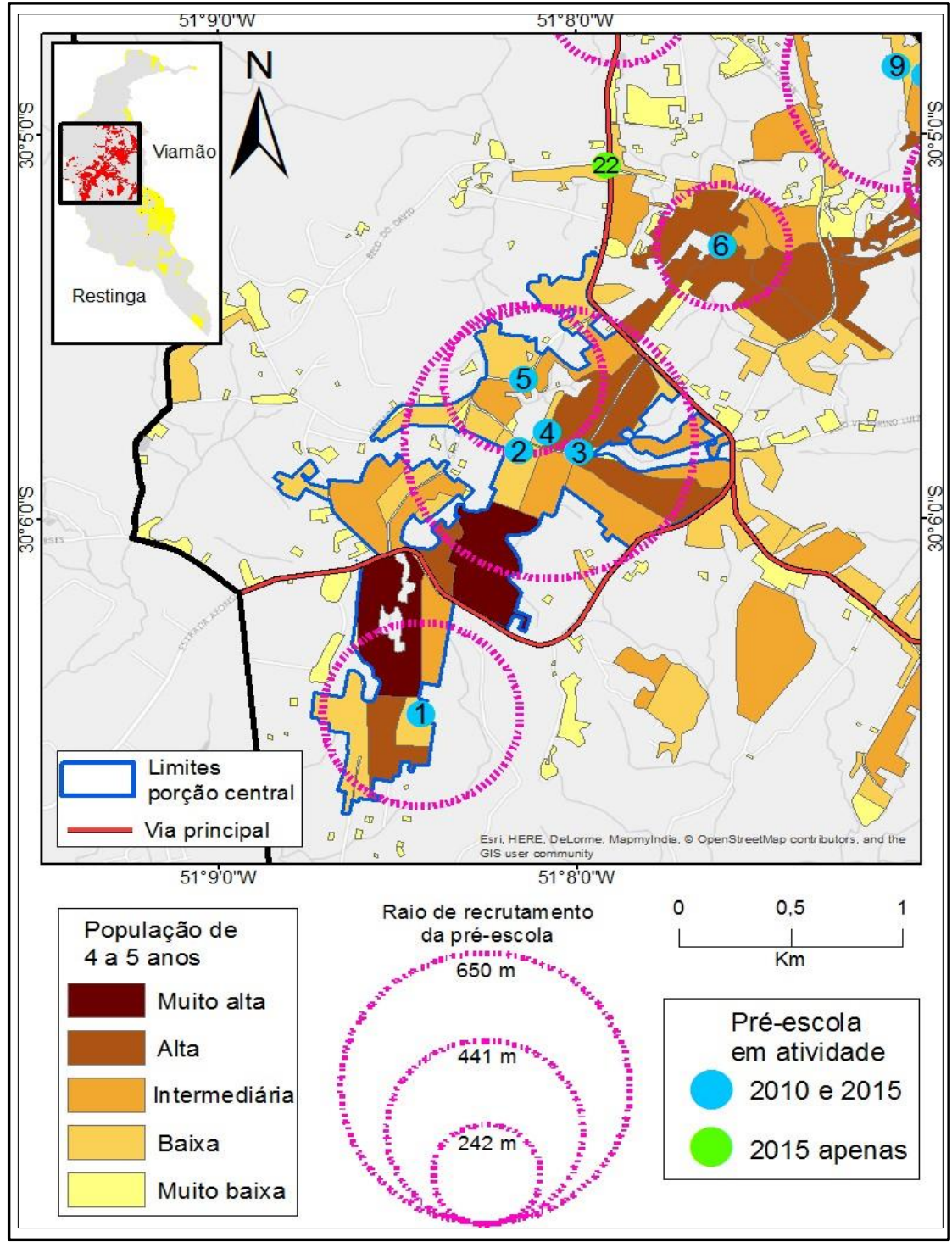

Figura 8 - Mapa de concentração de crianças de 4 a 5 anos e localização das pré-escolas nos anos de 2010 e 2015 com o raio de recrutamento para as pré-escolas de 2010 na porção oeste da região Lomba do Pinheiro.

Fonte: elaborado pelo autor (2017) com dados do IBGE (2010) e INEP (2010 e 2015). 
Por fim, a porção sudeste apresentava, em 2010, um total de 314 matrículas, o que nos indica uma taxa de atendimento de 35,2\% para esse ano. No entanto, em 2015 houve um expressivo aumento de 523 matrículas. Como se pode perceber na Figura 9, o aumento de matrículas ocorreu em decorrência do grande aumento de pré-escolas nessa porção da região. Enquanto em 2010 havia 10 equipamentos, em 2015 esse número subiu para 16. Apesar de ter ocorrido a desativação de uma pré-escola, houve o surgimento de outras sete.

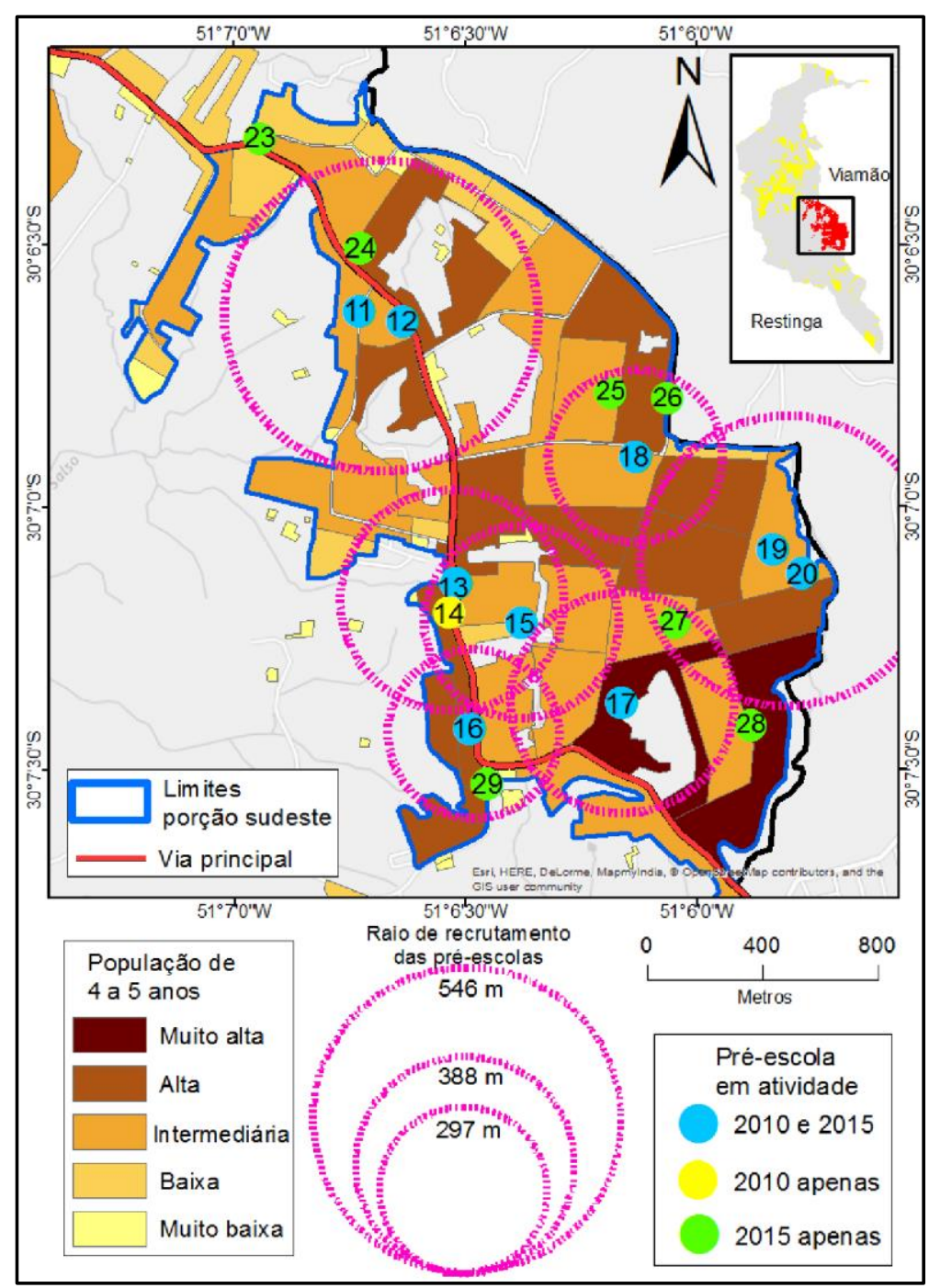

Figura 9 - Mapa de concentração de crianças de 4 a 5 anos e localização das pré-escolas nos anos de 2010 e 2015 com o raio de recrutamento para as pré-escolas de 2010 na porção sudeste da região Lomba do Pinheiro.

Fonte: elaborado pelo autor (2017) com dados do IBGE (2010) e INEP (2010 e 2015). 
No entanto, na medida em que em 2010 existiam em atividade nove equipamentos comunitários e um municipal, em 2015 destaca-se o surgimento de quatro equipamentos particulares, além do surgimento de outros dois equipamentos municipais.

Embora no ano de 2010 essa porção apresentasse uma carência bastante forte de pré-escolas para atender a população de 4 a 5 anos, em 2015 percebe-se um aumento bastante significativo de pré-escolas. Apesar de grande parte desses novos equipamentos ser do tipo particular, houve também a construção de duas novas pré-escolas municipais, fazendo com que a porção sudeste passasse a contar com três pré-escolas municipais (nos 12, 26 e 28) espacialmente bem distribuídas nesta porção da Lomba do Pinheiro. Em conjunto, esses equipamentos atendiam, em 2015, um total de 147 crianças, os equipamentos comunitários atendiam 298 e os particulares 78.

Com o objetivo de se identificar as áreas prioritárias para a implantação de pré-escolas na região Lomba do Pinheiro, houve a necessidade de ser escolhida apenas uma entre as três porções analisadas anteriormente. Isso não significa que apenas a porção selecionada tenha falta de pré-escolas, mas sim que ela é a que possui a maior carência desse tipo de equipamento entre as três previamente selecionadas. Nesse sentido, caso fôssemos levar em consideração as metas do PNE 2014 para o atendimento de crianças de 4 a 5 anos, as três porções não atenderiam à universalização do atendimento, uma vez que as porções nordeste, oeste e sudeste apresentaram para o ano de 2010, respectivamente, as seguintes taxas de atendimento: $49,8 \%, 40,3 \%$ e $35,2 \%$.

Ressalta-se que essas taxas embora sirvam como parâmetro, elas não são exatas, tendo em vista que são relativas ao ano de 2010. Todavia, provavelmente esse percentual não foi muito alterado nas porções nordeste e oeste, uma vez que não houve a construção de novas préescolas nessas duas porções no período 2010 - 2015. Já na porção sudeste, essa taxa provavelmente aumentou bastante, tendo em vista o surgimento de um elevado número de pré-escolas nesse setor. Destaca-se que, além da alteração do número total de matrículas nessas três porções, a redução do número de crianças na região Lomba do Pinheiro também contribuiu para o aumento das taxas de atendimento nas creches, pré-escolas e ensino fundamental. 
Como o objetivo deste trabalho não é especificar um número exato de equipamentos de ensino a serem construídos na região, mas apenas indicar as áreas prioritárias para a construção de novos equipamentos, optou-se por identificar as áreas prioritárias apenas na porção oeste, tendo em vista a sua baixa taxa de atendimento. Embora a porção sudeste tenha apresentado a taxa de atendimento mais baixa no período 2010-2015, constatou-se que essa porção recebeu a quase totalidade de investimentos em pré-escolas de toda região Lomba do Pinheiro. Dessa forma, apresenta-se o mapa da Figura 10 que indica as áreas prioritárias para a implantação de pré-escolas na porção oeste da região Lomba do Pinheiro.

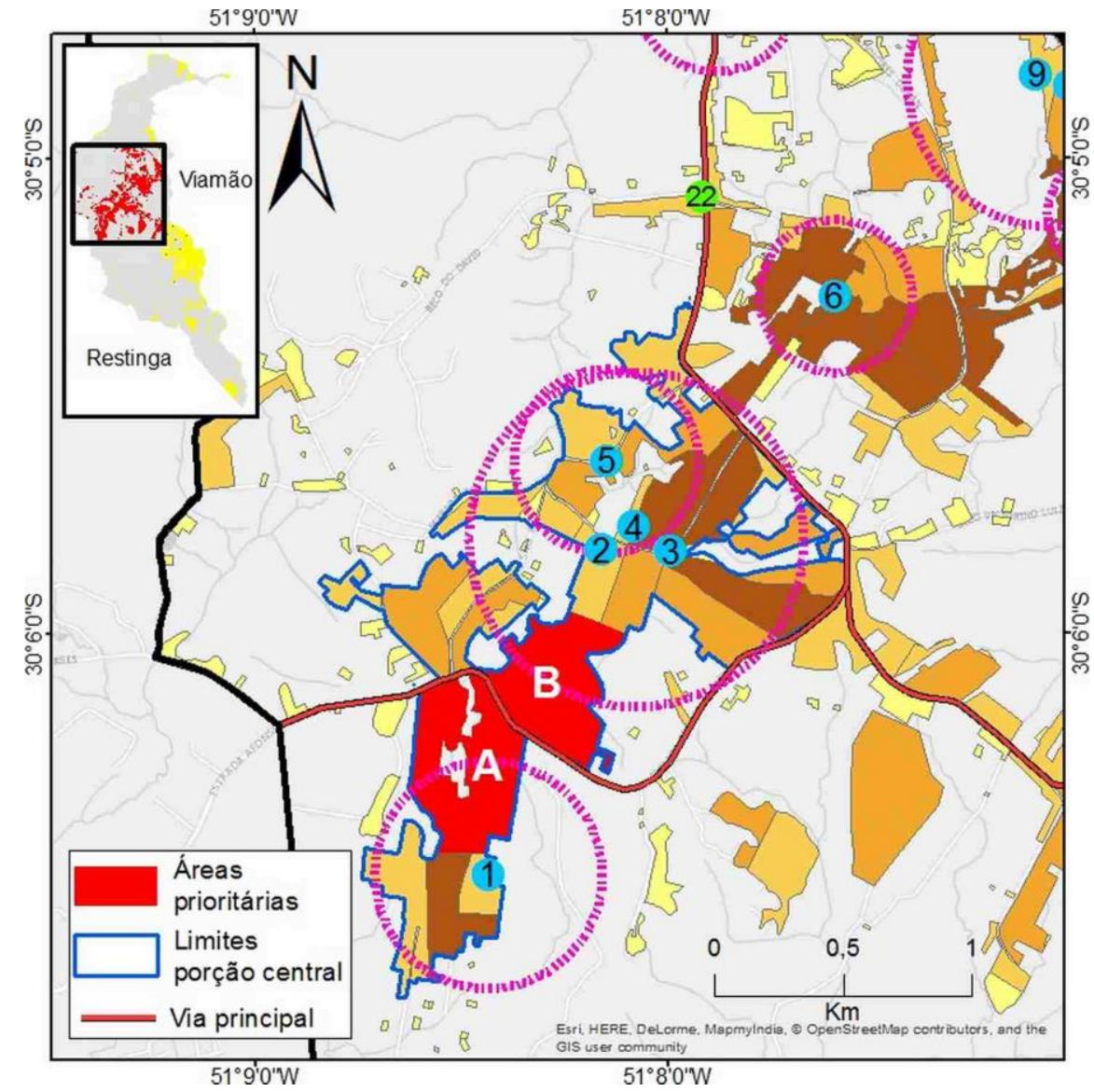

Figura 10 - Mapa de identificação das áreas prioritárias para a instalação de pré-escolas na porção oeste da região Lomba do Pinheiro.

Fonte: elaborado pelo autor (2017) com dados do IBGE (2010) e INEP (2010 e 2015).

Conforme indica o mapa da Figura 10, definiu-se duas áreas prioritárias para a implantação de pré-escolas na porção oeste da Lomba do Pinheiro e que se encontram representadas pela cor vermelha. Na área " $A$ " registrou-se um total de aproximadamente 77 crianças de 4 a 5 anos e o centro de gravidade dessa área se encontra a uma distância de cerca de 450 metros 


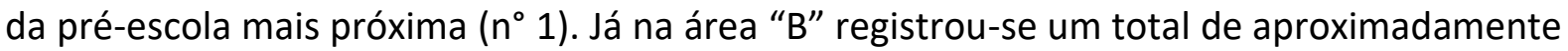
86 crianças de 4 a 5 anos e o seu centro de gravidade se encontra a uma distância de cerca de 590 metros da pré-escola mais próxima $\left(n^{\circ} 2\right)$.

\section{Conclusões}

A presente proposta metodológica de identificação de áreas prioritárias para a instalação de equipamentos de educação infantil ocorreu em duas escalas de análise: na primeira considerou-se o Município de Porto Alegre e as suas 17 regiões; na segunda selecionou-se as regiões prioritárias para a instalação de novos equipamentos de ensino. É importante destacar que as duas regiões mais centrais e antigas da cidade, o Centro e o Noroeste, apresentaram um número de matrículas superior à população total na faixa etária estudantil tanto para as creches como para as pré-escolas. Isso se deve ao fato de que não necessariamente as crianças que moram em uma determinada região estão matriculadas em um equipamento de ensino localizado nessa mesma região. Diversos fatores podem influenciar nessa questão, tais como, a reputação e status das escolas, a qualidade de ensino em cada estabelecimento, a maior ou menor facilidade de mobilidade dos habitantes, os locais de trabalho dos pais ou responsáveis, a opção dos pais por matricularem os filhos em instituições de ensino próximas ao seu local de trabalho, as características etárias da população que poderão influenciar a vida ativa de cada equipamento a médio ou longo prazo, entre outros. Um estudo qualitativo com a aplicação de questionário de forma amostral em alguns equipamentos de ensino poderia elucidar essas questões.

O uso de técnicas de Geoprocessamento para o cálculo do raio de recrutamento dos equipamentos de ensino, em conjunto com a aplicação do método dasimétrico de mapeamento, permitiu a identificação de áreas prioritárias para construção de novos equipamentos de educação infantil. No entanto, essa técnica apresentou algumas limitações no presente trabalho, tendo em vista que não foram considerados aspectos importantes do sistema urbano, como as conexões de vias urbanas, os diferentes graus de densificação e as barreiras físicas. Nesse sentido, novos estudos devem ser desenvolvidos levando-se em consideração esses aspectos, tendo em vista que eles influenciam diretamente na mobilidade urbana. Um exemplo seria explorar a área do urbanismo conhecida como Teoria da Sintaxe 
Espacial. Criada por Bill Hillier e seus colaboradores da Universidade de Londres, no começo da década de oitenta, essa teoria busca descrever a configuração do traçado e as relações entre espaço público e privado através de medidas quantitativas das vias da cidade, as quais permitem entender aspectos importantes do sistema urbano, tais como a acessibilidade e a distribuição de usos do solo.

Na região Partenon, constatou-se que a porção sudeste concentrava tanto um elevado número de crianças, assim como uma grande aglomeração de famílias de baixa renda. As creches presentes nessa porção eram comunitárias e se mostraram em número insuficiente para atender a demanda de matrículas. Nesse sentido, foram identificadas duas áreas como prioritárias para a construção de novas creches na porção sudeste da região Partenon. Já nas áreas de mais alta renda da região Partenon, foram constatadas melhores condições de acessibilidade das crianças com relação aos equipamentos de ensino, devido a maior oferta de matrículas provenientes de creches particulares. Destaca-se que, no período $2010-2015$, essa região contou com o aumento de apenas duas creches, refletindo diretamente em um pequeno aumento de matrículas na região. Nesse sentido, a demanda por creches na região Partenon é bastante superior à oferta, principalmente nas áreas de baixa renda da região.

Com relação à região Lomba do Pinheiro, embora no período 2010 - 2015 tenha ocorrido um considerável aumento no número de equipamentos de educação infantil na região, a maior parcela desses equipamentos foi do tipo particular. Ao se considerar a característica de baixa renda da população na Lomba do Pinheiro, o surgimento desses equipamentos teve como objetivo atender a uma restrita parcela da população que está a se instalar recentemente na região, mediante o surgimento de condomínios horizontais de alta renda. Ressalta-se que, após o ano de 2010, houve o surgimento de novas pré-escolas públicas e comunitárias na região, no entanto, a instalação desses equipamentos ficou concentrada na porção sudeste da região, enquanto nas porções oeste e nordeste não houve o surgimento de novas préescolas. Desse modo, foram definidas duas áreas prioritárias para a construção de pré-escolas no oeste da Lomba do Pinheiro, pelo fato de ser esta a porção com maior número de crianças mais distantes dos equipamentos de educação infantil.

Por fim, como todos os municípios brasileiros devem elaborar seus correspondentes planos de educação, a metodologia utilizada neste trabalho apresenta potencial para subsidiar os gestores educacionais no acompanhamento das diretrizes, metas e estratégias dos 
respectivos planos de educação no âmbito municipal. Além disso, ao se considerar que as bases de dados utilizadas nesta pesquisa (censo demográfico e censo escolar) possuem abrangência nacional, a aplicação dessa metodologia permitiria a comparação das diferentes realidades da oferta e demanda dos equipamentos de educação infantil nos municípios brasileiros.

\section{Referências}

Arantes, C.O. Mapeamento Educacional Urbano. Brasília: Secretaria Nacional de Educação Básica. Programa de Educação Básica nas Regiões Norte e Centro-Oeste - Monhangara, 1991. Disponível em: < http://www.dominiopublico.gov.br/download/texto/me001866.pdf >. Acesso em: 8 ago. 2017.

Arantes, C.O. Planejamento de Rede Escolar: Questões teóricas e metodológicas. Brasília: CEDATE, 1986. Disponível em:

http://www.dominiopublico.gov.br/pesquisa/DetalheObraForm.do?select action=\&co obra $=25516>$. Acesso em: 8 ago. 2017.

Batista, G.V., Bortoluzzi, S.D., ORTH, D.M. Geoprocessamento para determinação de acessibilidade aos equipamentos educacionais como ferramenta de apoio aos Estudos de Impacto de Vizinhança: estudo de caso na Planície do Campeche - Florianópolis/SC - Brasil. In: Simpósio Brasileiro de Sensoriamento Remoto, XV, 2011, Curitiba. Anais... Paraná: INPE, p.4177 - 4184. Disponível em: < http://marte.sid.inpe.br/col/dpi.inpe.br/marte/2011/07.06.19.37/doc/p1149.pdf >. Acesso em: 27 de mar., 2021. ISBN 978-85-17-00056-0

Brasil. Plano Nacional de Educação 2014-2024: Lei no 13.005, de 25 de junho de 2014, que aprova o Plano Nacional de Educação (PNE) e dá outras providências. Brasília: Câmara dos Deputados, Edições Câmara, 2014. 86 p.-(Série legislação; n. 125). Disponível em: < http://pne.mec.gov.br/18-planossubnacionais-de-educacao/543-plano-nacional-de-educacao-lei-n-13-005-2014 >. Acesso em: 27 ago. 2021.

Brau, L. Merce, M. e Tarrago M. Manual de urbanismo. Barcelona, LEUMT, 1980

CEBRACE. Planejamento de rede escolar: proposta metodológica - rede escolar urbana, $1^{\circ}$ grau. Rio de Janeiro.

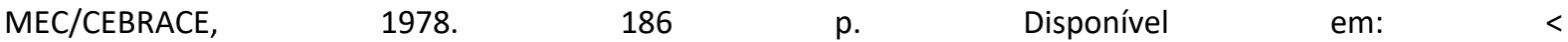
http://dominiopublico.mec.gov.br/pesquisa/DetalheObraForm.do?select action=\&co obra=28130 $>$. Acesso em: 27 de mar. 2021.

Hasenack, H.; Weber, E.; Marcuzzo, S.. Diagnóstico Ambiental de Porto Alegre: Geologia, Solos, Drenagem, Vegetação e Ocupação. Porto Alegre: Secretaria Municipal do Meio Ambiente, 2008. 84 p. ISBN 978-85-7727$129-0$

Holanda, D.C.. Metodologia para Avaliação da Acessibilidade na Localização de Escolas Públicas do Ensino Fundamental. Estudo de Caso: Fortaleza. Fortaleza, 2006. XVIII, 186 fl., Dissertação (Mestrado em Engenharia de Transportes) - Programa de Mestrado em Engenharia de Transportes, Centro de Tecnologia, Universidade Federal do Ceará, Fortaleza, 2006. Disponível em: < http://www.repositorio.ufc.br/handle/riufc/4908 >. Acesso em: 8 ago. 2017.

Instituto Brasileiro de Geografia e Estatística (IBGE). Base de informações do Censo Demográfico 2010: Resultados do Universo por setor censitário. Rio de Janeiro: IBGE 2011. Disponível em: < http://www.ipea.gov.br/redeipea/images/pdfs/base de informacoess_por_setor_censitario universo censo 2010.pdf >. Acesso em: 09 de abril, 2014.

Nahas, M. N. P., Pereira, M. A. M., Esteves, O. A., Gonçalves, E. Metodologia de construção do índice de qualidade de vida urbana dos Municípios brasileiros (IQVU-BR). In: XX ENCONTRO NACIONAL DE ESTUDOS 
POPULACIONAIS, 2006. Campinas, SP. Anais... Campinas: Unicamp, 2006. Disponível em: < http://www.abep.org.br/publicacoes/index.php/anais/article/view/1525 >. Acesso em: 27 ago. 2021.

Neves, F.H. Critérios de planejamento e implantação de equipamentos urbanos comunitários de educação e saúde: estudo de caso em Curitiba de 2010 a 2014. Dissertação (Mestrado - Área de Concentração: Ambiente Construído e Gestão,). Programa de Pós-Graduação em Engenharia de Construção Civil da Universidade Federal do Paraná. Curitiba, 2015. Disponível em: < https://acervodigital.ufpr.br/handle/1884/40828 >. Acesso em: 27 de fevereiro, 2021.

Oliveira, C. L. de. Avaliação da qualidade de vida em ambiente urbano em função da disponibilidade de serviços públicos. Estudo de caso: Canoas, RS. Dissertação (Mestrado em Engenharia Civil). Programa de Pós-Graduação em Engenharia Civil da Universidade Federal de Santa Catarina. Disponível em: < http://repositorio.ufsc.br/xmlui/bitstream/handle/123456789/89984/240723.pdf >. Acesso em: 28 de out. 2014.

Silva, L. L. Análise socioespacial urbana em Porto Alegre: vulnerabilidade social e localização de escolas públicas. 2013. 57 f. Monografia (Graduação) - Curso de Graduação de Bacharelado em Geografia, Universidade Federal do Rio Grande do Sul, Porto Alegre, 2013.

SILVEIRA, L. P.; KAWAKUBO, F. S. Mapa dasimétrico da densidade demográfica de Poços de Caldas (MG) utilizando técnicas de Sensoriamento Remoto e Geoprocessamento. In: Simpósio Brasileiro de Sensoriamento Remoto, XVI, 2013, Foz do Iguaçu, PR. Anais... INPE, 2013. P. 999 - 1005. Disponível em: < http://marte2.sid.inpe.br/rep/dpi.inpe.br/marte2/2013/05.29.00.32.37 >. Acesso em: 22 jul. 2017. ISBN:97885-17-00065-2

Souza, M.L. de. Mudar a cidade: uma introdução crítica ao planejamento e gestão urbanos. Rio de Janeiro. Bertrand Brasil, 2001. 560p. ISBN: 85-286-0856-5

Torres, H. G. Informação demográfica e políticas públicas na escala regional e local. Santiago de Chile: CELADE/CEPAL, out. 2005. In: Reunión de expertos sobre población y desarrollo local. P 33 - 53. Disponível em: < https://www.cepal.org/sites/default/files/publication/files/6855/S0600551 es.pdf >. Acesso em 27 de mar. 2021. ISSN: 1680-9041 